\title{
Immigration policy and internationally educated nurses in the United States: A brief history
}

\author{
Leah E. Masselink, PhDa, ${ }^{*}$ and Cheryl B. Jones, PhD, RN, FAAN ${ }^{b}$ \\ a Department of Health Services Management and Leadership, The George Washington \\ University, Washington, DC \\ b School of Nursing, University of North Carolina at Chapel Hill, Chapel Hill, NC
}

\begin{abstract}
Since the 1980s, U.S. policy makers have used immigration policy to influence the supply of nurses by allowing or restricting the entry of internationally educated nurses (IENs) into the U.S. workforce. The methods pursued have shifted over time from temporary visa categories in the 1980s and 1990s to permanent immigrant visas in the 2000s. The impact of policy measures adopted during nursing shortages has often been blunted by political and economic events, but the number and representation of IENs in the U.S. nursing workforce has increased substantially since the 1980s. Even as the United States seeks to increase domestic production of nurses, it remains a desirable destination for IENs and a target market for nurse-producing source countries. Hiring organizations and nurse leaders play a critical role in ensuring that the hiring and integration of IENs into U.S. health care organizations is constructive for nurses, source countries, and the U.S. health care system.
\end{abstract}

\section{Keywords}

Immigration; International educated nurses; Policy

During the past 20 years, the U.S. nursing workforce has experienced significant shifts between shortage and oversupply. Nursing employment trends have been described as "countercyclical" or working in opposition to cycles of economic growth or recession (Buerhaus, Auerach, \& Staiger, 2009). In times of shortage (or surplus), U.S. policy makers have sought to use immigration policy to influence the supply of nurses by allowing (or restricting) the entry of internationally educated nurses (IENs) into the U.S. work-force (Glaessel-Brown, 1998). The number of IENs working in the United States has increased from around 50,000 in the mid-1970s (Ea, 2007) to an estimated 165,000 (5.4\% of all nurses) in 2008, mostly from the Philippines, Canada, the United Kingdom, and India (Health Resource and Services Administration [HRSA], 2010). These trends have been shaped by immigration policy changes that were as much a function of broader political and economic conditions as of the nursing labor market changes they were intended to address. 
The purpose of this article was to provide an overview of immigration policy changes directed toward IENs since the 1980s; to describe the political, economic, and nursing labor market conditions under which they occurred; and to analyze their impact on the U.S. nursing workforce. To accomplish these goals, we review evidence from health care trade publications, Congressional records, government documents, news reports, and academic publications pertaining to immigration policy and nurse migration into the United States from the 1980s to the present.

\section{Historical Background}

The large-scale migration of nurses to the United States began under the Cold War-era Exchange Visitor Program, which was initiated in 1948 and sponsored by the American Nurses Association (Brush, 1993). The rapid growth of the U.S. hospital sector during the 1950s and 1960s created a huge demand for nurses. Many hospitals sponsored exchange nurses for work and study in the United States under the Exchange Visitor Program, first from European countries (Brush, 1993) and later from the Philippines (Choy, 2003).

The U.S. Immigration Act of 1965 ended a national origin quota system that heavily favored immigrants from Europe, enabling skilled workers from Asia, including thousands of nurses from the Philippines, to obtain immigrant visas (Brush, 2010). Migration opportunities for nurses were further extended when the H-1 occupational visa program, originally established to bring foreign workers to the United States in temporary jobs, was amended in 1970 to allow foreign workers to fill permanent positions (Choy, 2003).

\section{9 to 1993: Expansion and Contraction}

The entry of IENs into the United States began to expand in the late 1980s because of a confluence of factors including facility expansion, high acuity, changes in Medicare prospective payment, and declining nursing school enrollments created increased demand for nurses in U.S. health facilities (Glaessel-Brown, 1998), whereas low overall unemployment created a political environment amenable to the expansion of legal immigration in the United States. The 1989 Immigration Nursing Relief Act allowed nurses with H-1 work visas with at least 3 years' residency in the United States to adjust their status to permanent residency, and it exempted nurses and their families from H-1 visa quotas and backlogs (Choy, 2003). The Immigration Nursing Relief Act also created the H-1A visa, the first visa category specifically for nurses. The H-1A visa required prospective employers of IENs to attest to protections for U.S.-educated nurses (USENs) and to document their plans to reduce dependency on IENs.

Most H-1A visas were issued to Filipinos coming to the United States to work in hospitals and nursing homes (Nichols, 1995; Glaessel-Brown, 1998). Because H-1A nurses often worked in undesirable locations and shifts, they were not perceived as taking jobs from USENs, and the program was found to have no adverse effects on U.S. nurses' wages, benefits, or working conditions (Nichols, 1995; Glaessel-Brown, 1998). The Department of Labor loosened the attestation requirements in December 1990 (Tokarski, 1990), allowing thousands of IENs with expired H-1 visas to stay in the United States who otherwise would be sent home (Glaessel-Brown, 1998). 
Despite its documented success, the H-1A visa program also created dilemmas; the availability of IENs provided little incentive for the U.S. nursing sector to increase educational capacity in response to the shortage. The program has been described as a "national solution to a New York problem" because its primary outcome was the adjustment of status for Filipino nurses working in New York City (Nichols, 1995; Glaessel-Brown, 1998). It also showed that legislation is a slow way to address nursing shortages; by the time the H-1A visa program went into effect, the shortage it was intended to address was over. Nonetheless, the program was extended by 2 years past its original "sunset" date (from 1995 to 1997) to facilitate the entry of an additional 3,000 to 5,000 IENs in the face of another anticipated nursing shortage (Aston, 1996).

The Immigration Act of 1990 created another pathway for nurses to enter the United States - the H-1B visa, a category for skilled temporary workers. H-1B visa recipients were required to hold bachelor's degrees and to work in positions that required bachelor's degrees (Department of Homeland Security, 2008), so the category was theoretically open to IENs who fit these requirements. However, the visa was not heavily used for IENs because most employers did not require bachelor's degrees for nursing positions even after the Immigration and Naturalization Service revised the guidelines to allow nurses without 4year degrees to substitute work experience for the educational requirement and sped up processing in the early 2000s (Department of Homeland Security, 2008; Reilly, 2003). Department of Homeland Security (2008) records indicate that only a few hundred nurses have entered the United States on H-1B visas since the category was created. Nonetheless, the opening of a new category was representative of the expansion of migration pathways for IENs and other skilled immigrants during this period of economic growth and optimism. As of 1992, about 74,000 IENs worked in the United States, representing 3\% of the nursing workforce (HRSA, 1992).

The nursing shortage of the late 1980s ended in the early 1990s because of the decreased demand for nurses associated with economic recession including the return of some nurses to the workforce, managed care, and cost controls including the use of unlicensed nursing personnel (Glaessel-Brown, 1998; Aiken, 2007). The H-1A program remained in effect, but the number of IENs taking the U.S. nursing licensure examination (NCLEX) declined as the recession reduced legislative interest in and demand for IENs in U.S. hospitals (Figure 1).

\section{4 to 2001: New Opportunities for IENs}

The slowdown in nurse employment and the demand for IENs did not last long; declining nursing school enrollments (Figure 2) and the departure of many experienced USENs because of low salaries, poor working conditions, and increased paperwork and administrative duties limited the supply of nurses (American Association of Colleges of Nursing, 2013; Aiken, 2007; Buerhaus et al., 2009; Glaessel-Brown, 1998). The supply of nursing labor was further stretched as economic conditions improved and some experienced nurses retired early (Glaessel-Brown, 1998). The resulting shortage of nurses set the stage for a new period of expanded opportunities for IENs during the mid to late 1990s when new trade and immigration legislation gave them access to two new visa categories, the TN (or "Trade NAFTA [North American Free Trade Agreement]") and H-1C visas. 
The North American Free Trade Agreement, which was implemented in 1994, included provisions for the TN visa, a nonimmigrant visa category that allowed qualified professionals from Mexico and Canada to work in the United States for up to 3 years (Bieski, 2007). The program was immediately popular with nurses from Canada and, to a lesser degree, from Mexico. Approximately 6,000 nurses entered the United States during the first year of the program (Moore, 1996).

The new TN visa category prompted the nursing sectors in the United States, Canada, and Mexico to seek opportunities for development and collaboration (Squires, 2011) although its role as a pathway for nurse migration has been mostly limited to Canadian nurses (Little, 2007; Baumann, Blythe, Kolotylo, \& Underwood, 2004). Thirteen percent of IENs surveyed by the Commission on Graduates of Foreign Nursing Schools (2002) in 2000 to 2001 were Canadian, and all reported that they had entered the United States on TN visas. In Mexico, although the availability of the TN visa and the possibility of remittance income from nurses in the United States motivated the Mexican government to improve the infrastructure for nursing education, issues such as language, clinical training, licensure examination preparation, and "role transition" have limited the number of Mexican nurses coming to the United States (Squires, 2011). Some nurse recruitment firms have used the TN visa as an opportunity to promote training programs for Mexican nurses seeking to migrate to the United States, framing these initiatives as supporting "circular migration" of nurses between the United States and Mexico and improved nursing education and quality of nursing care in Mexico (Gabriel, 2013). Although the effects of both government and third-party initiatives to bring Mexican nurses to the United States have been limited so far, their efforts show how U.S. immigration policy changes and nursing employment opportunities influence the nursing sectors in other countries even outside of the usual source countries.

After the expiration of the H-1A program in 1997, legislators also sought to create another visa category specifically for nurses. They succeeded in crafting a new program with the Health Professions Shortage Area Nursing Release Act of 1997, which created the temporary $\mathrm{H}-1 \mathrm{C}$ visa category for nurses. The program's provisions meant that its impact was extremely limited; however, it allowed 500 nurses per year to work at U.S. hospitals on $\mathrm{H}-1 \mathrm{C}$ visas provided that hiring hospitals could attest to the protection of U.S.-educated nurses. Participating hospitals were also required to be located in designated health professional shortage areas, to have a minimum of 190 licensed beds, and to treat a minimum of 35\% Medicare and 28\% Medicaid patients. Participating hospitals could have no more than one third of their nursing staff composed of IENs, and IENs were only allowed to work at the hospital where they were originally hired. These strict guidelines left only 14 hospitals in 9 states eligible to hire IENs under the $\mathrm{H}-1 \mathrm{C}$ program. The program was so restrictive that it facilitated the entry of "only about a dozen nurses" into the United States by early 2004 (Greene, 2004).

Despite the limitations of both the $\mathrm{TN}$ and $\mathrm{H}-1 \mathrm{C}$ visa categories, the increased demand and expansion of visa options for IENs contributed to the growth in the number and representation of IENs in the U.S. nursing workforce during the late 1990s. The number of IENs taking the NCLEX increased, and by 2000, around 99,000 IENs worked in the United States, representing $4 \%$ of the nursing workforce (HRSA, 2000). However, the entry of 
IENs into the U.S. nursing workforce would soon be curbed dramatically by unforeseen events that have since changed migration globally.

\section{2 to 2004: Post-9/11 Slowdown}

The terrorist attacks of September 11, 2001, brought increased border security, slowdowns in visa processing, and economic recession, which combined to severely curtail all types of immigration to the United States. A nursing shortage quickly abated as U.S.-trained nurses returned to the workforce in response to the recession (Buerhaus et al., 2009), and legislation proposed to bring IENs into the United States failed. The bipartisan Rural and Urban Health Care Act (S 1259) proposing expansion of the H-1C visa category from 500 to 195,000 visas for IENs at any U.S. hospitals died in committee along with "almost every progressive immigration proposal" in the aftermath of the $9 / 11$ attacks (Randolph, 2004).

Representatives Sheila Jackson-Lee (TX) and Martin Frost (TX) reintroduced the Rural and Urban Health Care Act in 2003 (HR 87), but this bill died in committee again (http://www. govtrack.us/congress/bills/108/hr87), leaving the H-1C category with its original restrictive criteria in place until its expiration in 2009.

The processing of employment-based (EB) immigrant visas also slowed significantly after 9/11, which led to the loss of nearly 140,000 visa slots between 2001 and 2003 (Fong, 2005). Although the process sped up by 2004, slots for key IEN source countries (the Philippines, India, and China) were used up quickly in clearing the backlog (Evans, 2005). IENs' pathway into the United States was further complicated in 2003 when Congress approved the "VisaScreen" requirement to ensure that internationally educated professionals' English language abilities, education, and experience and training were the same as that of U.S.-educated workers. The requirement applied to nurses already in the United States (even foreign-born nurses who were educated in the United States) as well as incoming nurses ("Homeland Security Rules", 2004). Meanwhile, U.S. nursing schools experienced unprecedented increases in enrollment in 2003 and 2004, further bolstering supplies of domestically trained nurses entering the workforce (Figure 2) (American Association of Colleges of Nursing, 2013). As a result of the post-9/11 immigration, economic, and nursing labor market slowdowns, the number of IENs in the United States remained nearly flat between 2000 (99,000 IENs) and 2004 (101,000 IENs), and the proportion of IENs in the U.S. workforce declined to 3.7\% (HRSA, 2000; HRSA, 2006).

\section{5 to Present: Focus on EB Visas}

As the U.S. economy and nursing labor market began to stabilize in the mid-2000s, policy attention shifted from creating new temporary visa categories for nurses to "recapturing" EB visas lost in the slowdown after 9/11. The Philippines, India, and China all reached percountry quotas for EB visas in 2005, prompting legislators to consider several proposals allowing recapture of unused EB-3 visas for nurses from these countries. Proposals included a measure exempting visa holders' family members from numerical caps (more than doubling the number of available EB visas for health professionals) and a provision designating nursing as a "shortage occupation" not subject to EB visa caps ("Senate Budget Recognizes”, 2005; Kelley, 2006). Law-makers succeeded in recapturing 50,000 EB visas 
for nurses and physical therapists from the Philippines, India, and China in 2006 (Tsitouras \& Pabon Lopez, 2009), but the State Department announced later that year that all EB visa slots had been filled and no new visas would be issued while the existing applications were processed ("Government Caps", 2006).

Despite this setback, lawmakers continued to seek creative ways to maintain EB visa pathways for nurses. In 2007, they considered (as part of comprehensive immigration reform legislation) a proposal to replace the EB visa system with a points-based system, which gave preference to immigrants with advanced degrees and other desired qualifications. Despite bipartisan efforts to give greater consideration to nurses in the legislation, voting on the proposal was blocked, and the effort failed ("Senate Blocks Immigration Bill”, 2007). Legislators tried again in 2008 with a measure that proposed reclaiming 61,000 EB visas from past years for nurses from the Philippines and other key source countries in exchange for a \$1,500 per visa fee used to support nursing education programs at U.S. schools ("Senate Bill Aids Recruitment", 2007). The proposal was approved by the Senate, but the provisions were not included in the House bill.

Lawmakers in both parties kept working to protect EB visa slots for nurses in 2008 and 2009, but uncertain economic conditions and the re-entry of many U.S.-trained nurses into the workforce (Buerhaus et al., 2009) created a difficult political climate for their proposals. President Barack Obama himself was quoted rejecting the idea of bringing more IENs into the United States: "The notion that we would have to import nurses makes absolutely no sense. There are a lot of people [in the U.S.] who would love to be in that helping profession, and yet we just aren't providing the resources to get them trained-that's something we've got to fix" (Herbst, 2009). Representative Robert Wexler (D-FL) introduced emergency legislation (the Emergency Nursing Supply Relief Act) in 2008 and again in 2009 to set aside 20,000 EB visas per year for nurses and physical therapists. The bill also proposed additional funding for U.S. nursing schools and retention programs. Despite the support it garnered from both the American Hospital Association and the American Nurses Association, the bill never became law (Carlson, 2009). In 2009, Representative John Shadegg (R-AZ) introduced the Nursing Relief Act of 2009, a proposal to create a new nonimmigrant visa category (W visa) for nurses. It also died in committee (Carlson, 2009).

Although EB visas remained the mechanism by which most IENs enter the United States, long wait times for processing (known as "retrogression") have significantly slowed their entry for now. In March 2009, the State Department announced that the wait time for EB-3 visas (the category used by nurses) was extended to 6 years (http://www.travel.state.gov/ visa/bulletin/_bulletin 4428.html). As of October 2013, the average wait time had decreased to about 3 years, but waits for visa seekers from nurse-producing countries such as the Philippines (6-7 years) and India (10 years) remained significantly longer (http:// travel.state.gov/ visa/bulletin/bulletin 6062.html).

The slowdown in demand and visa availability for IENs in recent years occurred despite their increasing interest in pursuing work opportunities in the United States. The United States has opened several NCLEX testing centers overseas since 2005, and source countries 
such as the Philippines increased their production of nurses in response to perceived opportunities in the United States (Aiken, 2007). As a result, the economic recession reverberated in source countries because the number of IENs taking the NCLEX declined by more than 60\% between 2008 and 2012 (Figure 1) (National Council of State Boards of Nursing, 2008; National Council of State Boards of Nursing, 2012). The rapid reduction in U.S. employment opportunities in the United States created large stocks of unemployed nurses in source countries, especially the Philippines and India (Villeza, 2011), that produced huge numbers of nurses for the U.S. market. Some nursing schools in India closed down in response to the reduced demand for nurses in the United States ("Nurses Hit by Recession", 2009), and the Philippine government established a program sponsoring nurses to work in rural areas of the Philippines to provide opportunities for nurses unemployed because of the sudden lack of opportunities in the United States (Guillermo, 2009). Many hospitals in the Philippines have also established volunteer programs for unemployed nurses, some of which were shut down by the Philippine Department of Health for charging "training fees" to volunteer nurses (Department of Health, Republic of the Philippines, 2011). These events highlight the outsize influence of U.S. immigration policy developments in distant IEN source countries and the vulnerability of nurses who enter the field with the idea of migrating to the United States to unexpected changes in the U.S. economy and nursing labor market.

Despite the barriers faced by IENs since the Great Recession of 2008, the number of IENs in the United States still grew significantly between 2004 and 2008; IENs comprised over 8\% of newly licensed nurses, and their overall number grew to over 165,000 (5.4\% of all nurses) (HRSA, 2010). Falling numbers of new IENs taking the NCLEX likely mean that growth will be slower in the near future, but the overall U.S. employment picture for IENs will depend on ongoing political, economic, labor market, and societal debates.

\section{Discussion}

As a result of and sometimes despite U.S. immigration policies, both the number and the representation of IENs in the U.S. nursing workforce have increased substantially since the 1980s. Lawmakers proposed policies opening new pathways for IENs to enter the United States during times of nursing labor shortages, but because of the lag time in implementing legislation, their impact was often dwarfed by political and economic events at the time of implementation. The strongest example was the triple blow of 9/11, which created a difficult political environment for any immigration proposals despite a shortage of nurses before the attacks. Lawmakers still considered proposals "left over" from before $9 / 11$, but their motivation to pursue them was blunted by security concerns, a recession that brought many U.S.-trained nurses back to the workforce, and a massive slowdown in immigration processing.

This situation is exacerbated because of the sensitivity of domestic nurse employment to economic conditions. As of 2000, about $18 \%$ of registered nurses in the United States were not working in nursing (HRSA, 2000), creating a large pool of eligible nurses who could return to practice when the post-9/11 recession hit. Many U.S.-educated nurses who had left the field also reentered the workforce during the Great Recession of 2008 (Buerhaus et al., 
2009). When jobs in other sectors were threatened by recession, nursing employment experienced its most significant growth in decades because nurses took new jobs or increased their work hours to provide economic stability for their families. The largest growth occurred among nurses over age 50, who accounted for $77 \%$ of the total growth in nursing employment between 2001 and 2008 (Buerhaus et al., 2009). The availability of USENs ready to return to work in difficult economic conditions has reduced policy attention on nursing shortages and demand for new immigration pathways for IENs, at least for now.

Nursing workforce projections suggest that the reduced demand for nurses by U.S. health care organizations during the recession is likely temporary (Buerhaus et al., 2009; Cox, Lacey, \& O'Donnell, 2010). Continued shortages are predicted because of the aging of the U.S. population, stagnant nursing education capacity, and the retirement of an aging nursing work-force (Aiken, 2007; Cox et al., 2010). However, because of uncertainty that surrounds the implementation of the Patient Protection and Affordable Care Act and nurses' role in a reformed U.S. health care system, the degree to which predicted shortages will actually occur is unknown (Auerbach, Buerhaus, \& Staiger, 2011; Auerbach, Staiger, Muench, \& Buerhaus, 2013). As source countries continue massive production of nurses for export to other countries, the following unanswered questions remain: (1) Will IENs continue to find jobs in the United States or will they seek employment in other receiving countries? (2) Will U.S. health care organizations tap IENs as a solution to future nursing shortages in the United States? and (3) If so, what is the impact of hiring IENs on the quality of care provided by those organizations? Some evidence suggests that hospitals with high proportions of IENs have worse health outcomes, perhaps because of difficulties in communication or limitations of IENs' training (Neff, Cimiotti, Sloane, \& Aiken, 2013). Regardless of these challenges, many of the IENs already in the United States are here to stay (Aiken, 2007), and they play an important part in the U.S. health care system, particularly in urban hospitals and nursing homes (HRSA, 2010). As such, it is in the interest of hiring organizations and nurse leaders to find ways to provide IENs with the support and training they need as they transition into the U.S. workforce (Xu, 2010). The substantial growth of the IEN workforce in the last decade (a period of very limited visa opportunities) suggests that the United States remains a desirable destination for IENs whether U.S. immigration immigration policy facilitates their entry or not. Source countries will likely continue training nurses for the U.S. market regardless of the immediate availability of opportunities for them, and IENs will continue to pursue their "American dreams" even when their visa pathways are limited.

If immigration reform legislation succeeds, IENs will likely find increased opportunities to pursue these dreams. Regardless of the details of particular proposals, the immigration policies that have been discussed will likely privilege visas for skilled immigrants, which, while promising for individual IENs seeking job opportunities in the United States, can also been critiqued as a form of "brain drain" from source countries with already weak health systems. Because the nursing sectors of key source countries like India and the Philippines are built around an assumption that many nurses will migrate, it is not realistic to stop the flows of IENs from these countries. However, U.S. recruiters and health care organizations should do what they can to ensure that their recruitment of IENs can be absorbed by source country health systems and that IENs are not exploited in the process. The possibility of 
exploitation is a particular concern given the current pent-up demand for U.S. job opportunities among unemployed nurses in source countries. Many of these nurses pursued their education with hopes of migrating to the United States, and they could be especially vulnerable to irregular or exploitative recruitment schemes.

As this analysis has shown, immigration policies are slow and crude ways of addressing nursing shortages in the United States, and their unintended consequences are often more significant than their intended consequences. However, whether or not the policies have served their intended purpose, they have opened a variety of pathways for IENs into the U.S. nursing workforce. IENs have taken advantage of the opportunities, often without full knowledge of the opportunities and challenges that await them. In this context, hiring organizations and nurse leaders can play a critical role to ensure that the hiring and integration of IENs into U.S. health care organizations is constructive for nurses, source countries, and the U.S. health care system.

\section{REFERENCES}

Aiken LH. US nurse labor market dynamics are key to global nurse sufficiency. Health Services Research. 2007; 42(3):1299-1320. Pt 2. [PubMed: 17489916]

American Association of Colleges of Nursing. Percentage Change in Enrollments in Entry-Level Baccalaureate Nursing Programs: 1994 2012. 2013. Retrieved from. AACN Research and Data Center. Retrived from http://www.aacn.nche.edu/Media-Relations/EnrollChanges.pdf

Aston G. Hospitals win extension of visa program for nurses. AHA News. Oct 21.1996

Auerbach DI, Buerhaus PI, Staiger DO. Registered nurse supply grows faster than projected amid surge in new entrants ages 23-26. Health Affairs. 2011; 30(12):2286-2292. [PubMed: 22147855]

Auerbach DI, Staiger DO, Muench U, Buerhaus PI. The nursing workforce in an era of health care reform. New England Journal of Medicine. 2013; 368(16):1470-1472. [PubMed: 23594001]

Baumann, A.; Blythe, J.; Kolotylo, C.; Underwood, J. Immigration and emigration trends: A Canadian perspective. Ottawa: Nursing Sector Study Corporation. 2004. Retrieved from http://www.cnanurses.ca/cna/documents/pdf/publications/immigration_emigration_trends_e.pdf

Bieski T. Foreign-educated nurses: An overview of migration and credentialing issues. Nursing Economic\$. 2007; 25(1):20-23. 24. [PubMed: 17402674]

Brush BL. "Exchangees" or employees? The exchange visitor program and foreign nurse immigration to the United States, 1945-1990. Nursing History Review. 1993; 1:171-180. [PubMed: 8453399]

Brush BL. The potent lever of toil: Nursing development and exportation in the postcolonial Philippines. American Journal of Public Health. 2010; 100(9):894-909.

Buerhaus PI, Auerbach DI, Staiger DO. The recent surge in nurse employment: Causes and implications. Health Affairs. 2009; 28(4):w657-w668. [PubMed: 19525286]

Carlson J. Importing care: Some support visas for nurses; Obama doesn't. Modern Healthcare. 2009; 39(12):8-9.

Choy, CC. Empire of care: Nursing and migration in Filipino American history. Duke University Press; Durham, NC: 2003.

Commission on Graduates of Foreign Nursing Schools. Characteristics of foreign nurse graduates in the US workforce 2000-2001. Commission on Graduates of Foreign Nursing Schools; Philadelphia: 2002.

Cox K, Lacey S, O’Donnell R. Don't be fooled: Demographics ensure nursing shortage will return with better economy. Modern Healthcare. 2010; 40(50):25. [PubMed: 21322353]

Department of Health, Republic of the Philippines. Termination of all "nurse volunteer programs," "volunteer training programs," and all similar or related programs in all DOH-retained hospitals. 2011:2011-0238. Departmental Memo No. 
Department of Homeland Security. Improving the processing of "Schedule A" nurse visas. 2008. Retrieved from http://www.dhs.gov/xlibrary/assets/cisomb_recommendation_36.pdf

Ea, EE. Facilitating acculturation of foreign-educated nurses. Online Journal of Issues in Nursing. 2007. Retrieved from http://nursingworld.org/MainMenuCategories/ANAMarketplace/ ANAPeriodicals/OJIN/TableofContents/vol132008/No1Jan08/ArticlePreviousTopic/ ForeignEducatedNurses.html

Evans M. Will work for visa. Bill would boost visas for skilled workers. Modern Healthcare. 2005; 35(2): 16 .

Fong T. Nurse visa crisis eases. Modern Healthcare. 2005; 35(24):28. [PubMed: 16617722]

Gabriel C. NAFTA, skilled migration, and continental nursing markets. Population, Space and Place. 2013; 19(4):389-403.

Glaessel-Brown EE. Use of immigration policy to manage nursing shortages. Image. 1998; 30(4):323327.

Govt. caps on immigrant visas seen stifling recruitment of overseas RNs. AHA News. Nov 27.2006

Greene J. Hitting the visa limit. Hospitals \& Health Networks. 2004; 78(1):16.

Guillermo JB. DoLE officials invite applicants to the NARS program. Manila Bulletin. Mar 17.2009

Health Resources and Services Administration. The registered nurse population: Findings from the 2000 National Sample Survey of Registered Nurses. 1992. Retrieved from http://bhpr.hrsa.gov/ healthworkforce/rnsurveys/rnsurvey 1992.pdf

Health Resources and Services Administration. The registered nurse population: Findings from the 2000 National Sample Survey of Registered Nurses. 2000. Retrieved from http://bhpr.hrsa.gov/ healthworkforce/rnsurveys/rnsurvey2000.pdf

Health Resources and Services Administration. The Registered Nurse Population: Findings from the 2004 National Sample Survey of Registered Nurses. 2006 Retrieved from ftp://ftp.hrsa.gov/bhpr/ workforce/0306rnss.pdf.

Health Resources and Services Administration. The registered nurse population: Findings from the 2008 National Sample Survey of Registered Nurses. 2010. Retrieved from http://bhpr.hrsa.gov/ healthworkforce/rnsurvey/2008/nssrn2008.pdf

Herbst, M. Immigration: More foreign nurses needed?. BusinessWeek Online. Jun 22. 2009 Retrieved from http://www.businessweek.com/bwdaily/dnflash/content/jun2009/db20090619_970033.htm

Homeland Security rules mandate screening of foreign nurses seeking US employment. Nursing Economic\$. 2004; 22(5):287.

Kelley J. Immigration measure seen helping hospitals address RN staffing needs. AHA News. Sep 18.2006

Little L. Nurse migration: A Canadian case study. Health Services Research. 2007; 42(3):1336-1353. Pt 2. [PubMed: 17489918]

Moore JD Jr. This week in healthcare: Congress nixes foreign nurse program. Modern Healthcare. 1996; 26(15):24.

National Council of State Boards of Nursing. NCLEX examination pass rates. 2008. Retrieved from https://www.ncsbn.org/Table_of_Pass_Rates_2008.pdf

National Council of State Boards of Nursing. NCLEX examination pass rates. 2012. Retrieved from https://www.ncsbn.org/Table_of_Pass_Rates_2012.pdf

Neff DF, Cimiotti J, Sloane DM, Aiken LH. Utilization of non-US educated nurses in US hospitals: Implications for hospital mortality. International Journal for Quality in Healthcare. 2013; 25(4): 366-372.

Nichols BL. The Immigration Nursing Relief Act of 1989. Imprint. 1995; 42(3):28-31. 60. [PubMed: 7498923]

Nurses hit by recession. Times of India, 12 May. 2009. Retrieved from http:// articles.timesofindia.indiatimes.com/2009-05-12/bangalore/28190494_1_nursing-institutes-lakhnurses-nursing-colleges

Randolph LB. Brave new world. Nursing Management. 2004; 35(1):4-5. [PubMed: 15064563]

Reilly P. Importing controversy: US hospitals' recruitment of foreign nurses stirs debate as poorer countries struggle with staffing shortages of their own. Modern Healthcare. 2003; 33(14):20-24. 
Senate bill aids recruitment of overseas RNs. AHA News. Oct 29.2007

Senate blocks immigration bill and its tough visa rules on RNs. AHA News. Jul 9.2007

Senate budget recognizes need for foreign RNs to help stem shortages. AHA News. Oct.2005:31.

Squires A. The North American Free Trade Agreement (NAFTA) and Mexican nursing. Health Policy and Planning. 2011; 26(2):124-132. [PubMed: 20595330]

Tokarski C. Government eases up on foreign nurses. Modern Healthcare. 1990; 20(49):2.

Tsitouras, DJ.; Pabon Lopez, M. Flatlining: How the reluctance to embrace immigrant nurses is mortally wounding the US healthcare system. Social Science Research Network Working Paper. 2009. Retrieved from http://ssrn.comlabstract=1434169

Villeza, L. Behind the nursing glut. Business World. Mar 24. 2011 Retrieved from http:// www.bworldonline.com/content.php?title=Behind_the_nursing_glut\&id=28595

$\mathrm{Xu}$ Y. Transitioning international nurses: An outlined evidence-based program for acute care settings. Policy, Politics, \& Nursing Practice. 2010; 11(3):202-213. 


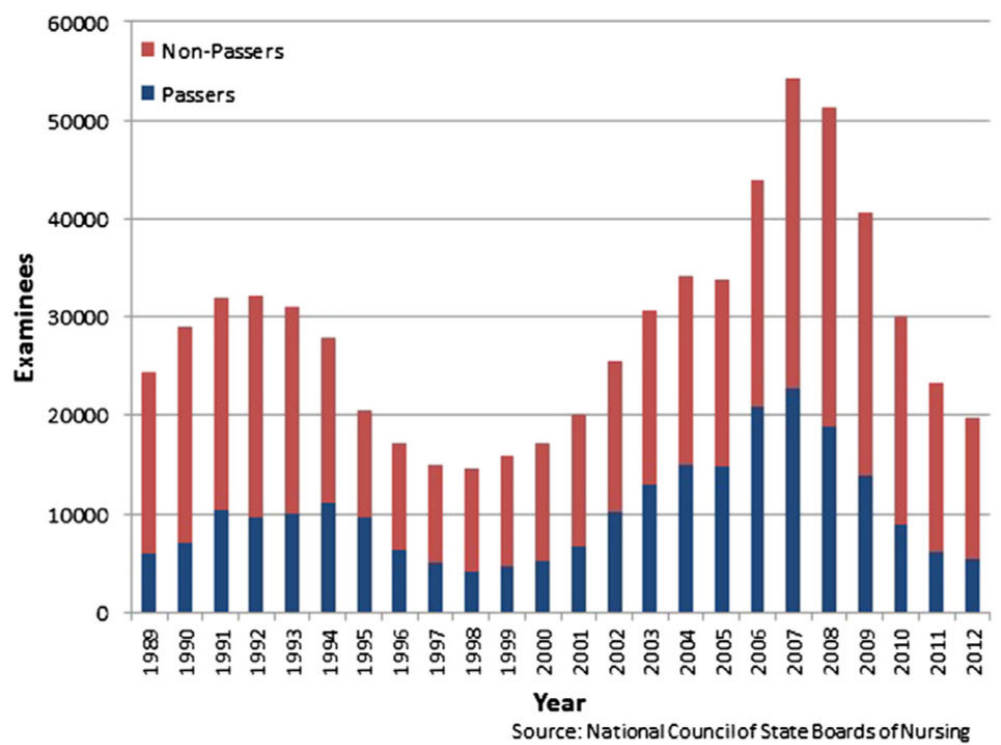

Figure 1.

Internationally educated NCLEX-RN examinees by year (1989-2012). 


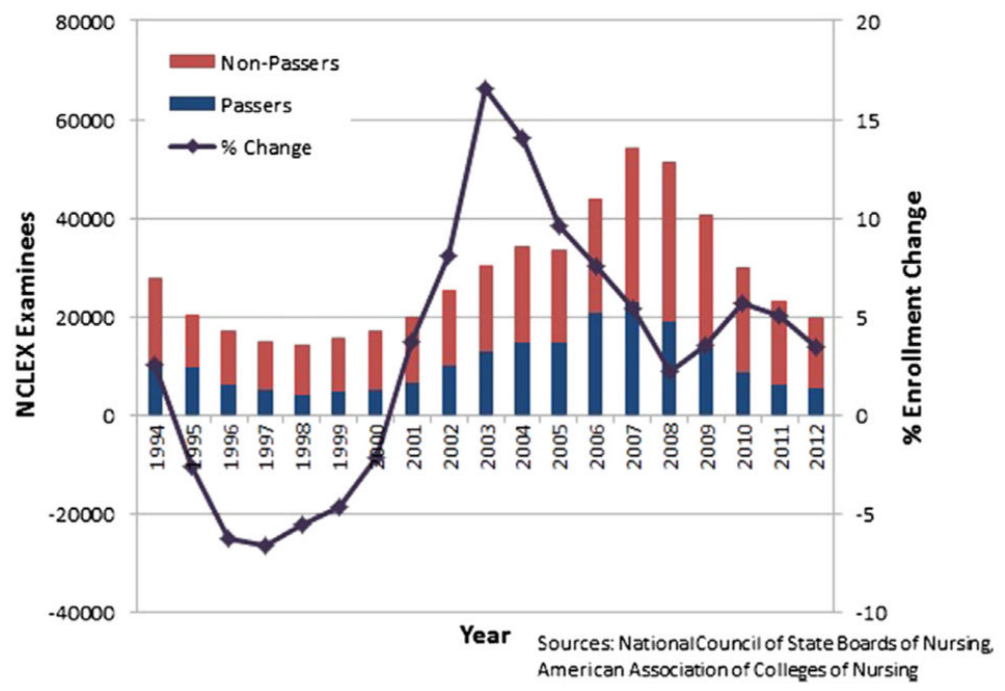

Figure 2.

Changes in U.S. Baccalaureate nursing program enrollment vs. Internationally educated NCLEX examinees (1994-2012). 